\title{
Treatment and seroconversion in a cohort of children suffering from recent chronic Chagas infection in Yoro, Honduras
}

\author{
Josep M Escribà̀'+', Elisa Ponce², Alberto de Dios Romero', Pedro Albajar Viñas ${ }^{3}$, Andrea Marchiol', \\ Glòria Bassets', Pedro Pablo Palma', M Angeles Lima', Concepción Zúniga ${ }^{4}$, Carlos Ponce ${ }^{2}$
}

${ }^{1}$ Médécins Sans Frontières-Spain, c/ Nou de la Rambla 23, E-08001 Barcelona, Spain ${ }^{2}$ Central Reference Laboratory for Chagas Disease and Leishmaniasis ${ }^{4}$ National Chagas Disease Prevention and Control Program, Secretariat of Health, Tegucigalpa, Honduras ${ }^{3}$ Laboratório de Doenças Parasitarias - Medicina Tropical, Instituto Oswaldo Cruz-Fiocruz, Rio de Janeiro, RJ, Brasil

Between 1999-2002, Médécins Sans Frontières-Spain implemented a project seeking to determine the efficacy and safety of benznidazole in the treatment of recent chronic Chagas disease in a cohort of seropositive children in the Yoro Department, Honduras. A total of 24,471 children were screened for Trypanosoma cruzi IgG antibodies through conventional enzyme-linked immunosorbent assays (ELISA) on filter paper. Recombinant ELISA (0.93\% seroprevalence) showed 256 initially reactive cases, including 232 confirmed positive cases. Of these, 231 individuals were treated with benznidazole $(7.5 \mathrm{mg} / \mathrm{kg} /$ day) for 60 days and were followed with a strict weekly medical control and follow-up protocol. At the end of the project, 229 patients were examined by the Honduras Secretariat of Health for post-treatment serological assessments; $88.2 \%$ seroconverted after 18 months and $93.9 \%$ seroconverted after three years. No differences were found in the seroconversion rates according to age or sex. Most of the side effects of the treatment were minor. These results support the argument that in areas where T. cruzi I is predominant and in areas affected by T. cruzi II, when vector transmission has been interrupted, Chagas disease diagnosis and treatment are feasible, necessary and ethically indisputable.

Key words: Chagas disease - drug therapy - benznidazole - indeterminate form - Honduras

In the past 15 years, the burden of Chagas disease (also known as American trypanosomiasis) has significantly decreased as a result of a number of multinational regional initiatives promoted and coordinated by the Pan American Health Organisation (PAHO). According to recent estimates and information from 21 countries where the disease is endemic, 8-9 million people are infected by the Trypanosoma cruzi parasite and around 40 million are at risk of becoming infected (PAHO 2006, Scofield et al. 2006). These estimates are 50\% lower than the infection rate in 1990 . However, Chagas disease continues to have a considerable impact on public health in the Americas and around 200,000 new cases and 20,000 deaths occur every year (WHO 2005, Moncayo \& Ortiz-Yanine 2006).

After the disease was discovered by Carlos Chagas in Brazil in 1909, human cases were reported in El Salvador in Central America in 1913 (Segovia 1913). In Honduras, Chagas disease has been known since 1960, but the first nationwide sero-epidemiological and entomological studies were not carried out until the 1970s and 1980s. These studies showed the presence of two main vectors (Rhodnius prolixus and Triatoma dimidiata) related to

Financial support: Médécins Sans Frontières-Spain, Honduras Secretariat of Health

+Corresponding author: 22766jej@comb.cat

Received 5 May 2009

Accepted 7 October 2009 housing conditions and showed the seroprevalence of $T$. cruzi in different areas of the country. Approximately 300,000 people are infected and this estimate includes a $6 \%$ rate of seroprevalence of $T$. cruzi infection among the overall population and a $3 \%$ rate among schoolchildren in rural areas. These rates are mostly linked to vector transmission (República de Honduras 2003a, 2004, Yamagata \& Nakagawa 2006).

The Honduras Secretariat of Health (HSH) is focused on controlling this pathogen and, within the Central American Initiative for Chagas Disease Control framework, initiated the 2003-2007 National Strategic Plan for the Prevention and Control of Chagas Disease. This plan included technical support from the PAHO/WHO and broad national and international multi-sector participation (República de Honduras 2003a, b, Ponce 2007). One of the main objectives of the plan was to scale up diagnostic and treatment coverage. With this goal in mind, Médécins Sans Frontières-Spain (MSF-E) collaborated with the HSH to develop a comprehensive strategy to combat Chagas disease that included vector control activities (such as spraying with residual insecticides), community-based education, the training of medical staff, diagnosis and etiological treatment with benznidazole. In addition, the efficacy and safety of benznidazole in asymptomatic infected children was assessed.

\section{PATIENTS, MATERIALS AND METHODS}

Study area and patients - This project was implemented between July 1999-December 2002 in Yoro Department, Honduras, located in the country's central mountainous area where the infection is endemic and highly prevalent. The study required the selection of an 
endemic area where interrupted vector transmission was under surveillance, high seroprevalence rates existed and teams with the operational capacity to provide and supervise treatment were available.

Asymptomatic infected children under the age of 13 years were included in the study. Individuals with severe malnutrition, anaemia or other underlying diseases were excluded from the study and, depending on the severity of these conditions, were referred to the Primary Health Care Units or to the rural area hospital. Between the end of the project and September 2005, HSH was responsible for patient treatment and for carrying out post-treatment serological assessments to confirm cure rates. The study protocol was approved by the HSH of the Ministry of Health and by MSF-E.

Baseline evaluation and drug management - T. cruzi infection was detected using serological tests with enzyme-linked immunosorbent assay (ELISA) with crude antigen (Chagatest ELISA; Wiener Lab, Rosario, Argentina). The blood samples were obtained by digital puncture at the Yoro Hospital and spotted on filter paper. A second ELISA test, prepared with recombinant $T$. cruzi antigens (Chagatest recombinant ELISA, version 3.0; Wiener Lab, Rosario, Argentina), was performed using an ELISA plate reader [optical density (OD) at $450 \mathrm{~nm}$ ]. This second test was used to confirm the results of samples considered reactive during visual readings (ELISA crude antigens) and to validate $10 \%$ of those samples testing negative at the Central Reference Laboratory for Chagas disease and Leishmaniasis in Tegucigalpa.

The seropositive children started supervised treatment with benznidazole (Radanil ${ }^{\circledR}$, Roche) and were given a 7.5 $\mathrm{mg} / \mathrm{kg}$ dose two times a day for 60 days. According to the follow-up protocol, adverse reactions were recorded and periodic clinical examinations were completed. In order to determine the treatment efficacy, two serological assessments using Chagatest recombinant ELISA were conducted. The children who remained seropositive 18 months after chemotherapy, despite presenting a decrease in their antibody titres, were followed until 36 months after treatment. These assessments were carried out by simultaneously processing the post-treatment filter paper blood samples and the pre-treatment samples preserved at $-20^{\circ} \mathrm{C}$.

Informed consent - Parents or guardians of children registered for treatment were informed about its potential benefits and possible risks, including potential adverse reactions and how to proceed if they appeared. Once they were informed, the corresponding signed consent was requested.

Assessment of treatment outcomes - The results were measured in terms of (i) negative seroconversion, defined as the disappearance of antibodies to T. cruzi, (ii) tendency to seroconvert, defined as $\mathrm{a} \geq 75 \%$ reduction in OD readings for serological tests compared to baseline values (equivalent to a decrease of $\geq 2$ dilutions of antibody titres) and (iii) average reduction of antibody titres after the treatment on repeated serological tests.

Statistical analysis - Normalised differences in antibody titres were calculated in consecutive assessments and comparisons to pre-treatment baseline values were made with the following equation: [(final antibody titres - initial antibody titres)/initial antibody titres] x 100 . Likewise, differences between the baseline and posttreatment $T$. cruzi median antibody titres were compared using the Wilcoxon ranked sum test. Seroconversion rates at 18 and 36 months after treatment were compared using the McNemar test. Mann-Whitney U-test and Kruskal-Wallis test were used to compare differences in T. cruzi antibody titres according to age and sex, while Chi-square or Fisher's exact tests were used to compare differences in seroconversion rates. The statistical significance was set at $5 \%$.

\section{RESULTS}

Screened subjects and seropositive cases - A total of 24,771 children out of a census of 25,563 (96.9\% coverage) were screened. The children lived in five municipalities in the Yoro Department and ranged in age from nine months to 12 years; $15,746(64 \%)$ were under the age of five years and 9,025 (36\%) were between 5-12 years of age. Two hundred and fifty six cases were initially found to be reactive by the conventional ELISA (crude antigens), including 232 cases that were confirmed to be positive with the Chagatest recombinant ELISA $(0.93 \%$ seroprevalence). Of these serologically-positive children, $65(28.1 \%)$ were under the age of five years; $196(84.5 \%)$ lived in localities previously infested with $R$. prolixus and $36(15.5 \%)$ lived in areas previously infested with $T$. dimidiata. The median time between spraying and the onset of treatment was eight months (interquartile range 4-12.5 months). Nearly all of the cases were detected in asymptomatic children in the indeterminate or early chronic phase of Chagas disease; the exception was an acute case which presented with Romaña's sign.

Treated patients and follow-up - A total of 231 seropositive children started the treatment. Of these, 229 patients $(99.1 \%)$ were followed for at least 18 months and a subset of 27 patients were monitored for up to 36 months after treatment. Three children failed to complete the 60-day therapeutic protocol, but were treated for almost a full course (43, 49 and 50 days of treatment), and one case of acute Chagas disease was treated for 30 days. These four patients had seroconverted by the 18 month follow-up.

Adverse events - Unwanted effects were frequently observed during the treatment; most side effects were minor or moderate and most did not require the discontinuation of medication. Only three patients interrupted the treatment within seven weeks due to severe unwanted neurological effects (peripheral neuropathy of the lower limbs). The most common adverse effects were gastrointestinal disorders ( $\mathrm{n}=62$ cases, $26.8 \%$ of the total), followed by dermatological conditions $(\mathrm{n}=30,13 \%)$ and neurological problems $(n=24,10.4 \%)$ (Table I). No significant differences were seen in the proportion of adverse effects according to age or sex. The most frequent adverse gastrointestinal episodes included epigastralgia and/or abdominal pain ( $\mathrm{n}=42$ episodes), nausea and/or vomiting $(\mathrm{n}=17)$, anorexia $(\mathrm{n}=12)$, diarrhoea 
$(\mathrm{n}=5)$ and hepatitis $(\mathrm{n}=1)$; these mostly appeared during the first week after treatment. Dermatological conditions included local or widespread pruritus $(n=33)$, more or less widespread maculopapular exanthema (n $=12)$ and urticaria $(n=1)$; these conditions more frequently occurred 2-3 weeks after treatment began. The most common neurological problems include peripheral polyneuritis $(n=6)$, headaches $(n=5)$, arthromyalgia in the lower limbs $(n=4)$ and seizures $(n=2)$. No deaths occurred during treatment and no hospitalisations occurred due to benznidazole-related adverse events.

Serological outcomes - Post-therapeutic serological results are shown in Tables II, III and IV. Quantitative analysis of changes in the antibody titres confirmed significant global differences in both the first (Table II) and second assessments (Table III).

After 18 months, the overall seroconversion rate was $88.2 \%$ (95\% CI from $84-92.4 \%$ ); it increased to $93.9 \%$ (95\% CI from 90.8-97\%) at the end of the three-year follow-up, although this increase was not statistically significant (Table IV). Thirteen out of the 27 cases $(48.1 \%)$ that remained seropositive 18 months after treatment yielded negative serological results at 36 months after chemotherapy; 19 of the $27(70.4 \%)$ cases tended to seroconversion (i.e., had OD readings that had decreased by $\geq 75 \%$ ). These patients were mostly younger than 10 years of age $(10 / 13,76.9 \%$ and $13 / 19,68.4 \%$, respectively) (Table IV).

Two children under the age of five years did not show any significant variation in the antibody titres despite completing the treatment. Their dwellings were thoroughly checked to eliminate the possibility of reinfection. Between 1-2 months after the benznidazole treatment ended they started and completed treatment with nifurtimox (Lampit ${ }^{\circledR}$, Bayer) at $8 \mathrm{mg} / \mathrm{kg} /$ day for 30 days. Their last post-treatment serological assessments were done at 48 months and 51 months and although the final results were positive, antibody titres in both cases had decreased by about $40 \%$.

Of the 229 treated patients who were monitored for up to 18 months post-treatment, $85.2 \%$ (95\% CI from $80.5-89.8 \%$ ) had decreased OD by $\geq 75 \%$ compared to the baseline values. By the end of the follow-up period (36 months), 93.4\% (95\% CI from 90.2-96.7\%) of patients showed $\mathrm{a} \geq 75 \%$ reduction in OD; this difference was statistically significant. Nineteen out of the 34 cases

TABLE I

Distribution of benznidazole-related side effects among patients that started treatment in Médécins Sans Frontières-Spain and Honduras Secretariat of Health project in Yoro, Honduras, 1999-2005 ( $\mathrm{n}=231$ )

\begin{tabular}{lccccc}
\hline & & \multicolumn{4}{c}{ Side effects } \\
\cline { 3 - 6 } & & Gastrointestinal & Dermatological & Neurological & Total \\
& & $\mathrm{n}$ & $\mathrm{n}$ & $\mathrm{n}$ & $\mathrm{n}(\%)$ \\
\hline Age (years) & $<5$ & 18 & 10 & 7 & $65(28.1)$ \\
& $5-9$ & 19 & 13 & 5 & $71(30.7)$ \\
& $\geq 10$ & 25 & 14 & 12 & $95(41.1)$ \\
Gender & Male & 31 & 16 & 9 & $105(45.5)$ \\
& Female & 31 & $30(13.0)$ & $24(10.4)$ & $126(54.5)$ \\
Total (\%) & & $62(26.8)$ & & & 231 \\
\hline
\end{tabular}

in the boxes in the same row, patients can be repeated. The same patient can have side effects of different nature.

TABLE II

Comparison of Trypanosoma cruzi antibody titres between baseline values and 18 months after treatment in Médécins Sans Frontières-Spain and Honduras Secretariat of Health project in Yoro, Honduras, 1999-2005 ( $\mathrm{n}=229)$

\begin{tabular}{|c|c|c|c|c|c|}
\hline & & $\mathrm{n}$ & $\begin{array}{c}\text { Baseline } \\
\text { Median (IQR) }\end{array}$ & $\begin{array}{c}18 \text { months } \\
\text { Median (IQR) }\end{array}$ & $\mathrm{p}$ value ${ }^{a}$ \\
\hline \multirow[t]{3}{*}{ Age (years) } & $<5$ & 65 & $2.14(1.74-2.44)$ & $0.34(0.33-0.34)$ & $<0.001$ \\
\hline & $5-9$ & 70 & $2.18(1.68-2.51)$ & $0.33(0.32-0.34)$ & $<0.001$ \\
\hline & $\geq 10$ & 94 & $2.26(1.84-2.54)$ & $0.33(0.32-0.34)$ & $<0.001$ \\
\hline \multirow[t]{2}{*}{ Gender } & Male & 104 & $2.21(1.84-2.64)$ & $0.34(0.33-0.34)$ & $<0.001$ \\
\hline & Female & 125 & $2.21(1.74-2.46)$ & $0.33(0.32-0.34)$ & $<0.001$ \\
\hline Total & & 229 & $2.18(1.77-2.48)$ & $0.33(0.32-0.34)$ & $<0.001$ \\
\hline
\end{tabular}

$a$ : $\mathrm{p}$ value for Wilcoxon ranked sum test; IQR: interquartil range. 
TABLE III

Comparison of Trypanosoma cruzi antibody titres between 18-36 months after treatment in Médécins Sans Frontières-Spain and Honduras Secretariat of Health project in Yoro, Honduras, 1999-2005 ( $\mathrm{n}=27)$

\begin{tabular}{lccccc}
\hline & & & 18 months & 36 months \\
& & $\mathrm{n}$ & Median (IQR) & Median (IQR) & p value \\
\hline Age (years) & $<5$ & 7 & $1.29(1.12-2.24)$ & $0.33(0.32-1.46)$ & 0.018 \\
& $5-9$ & 9 & $1.16(0.97-1.29)$ & $0.32(0.32-0.70)$ & 0.008 \\
& $\geq 10$ & 11 & $1.14(1.12-1.32)$ & $0.62(0.33-0.68)$ & 0.003 \\
Gender & Male & 15 & $1.24(1.12-1.46)$ & $0.58(0.33-0.72)$ & 0.001 \\
& Female & 12 & $1.12(0.95-1.30)$ & $0.33(0.31-0.64)$ & 0.002 \\
Total & & 27 & $1.18(1.12-1.32)$ & $0.33(0.32-0.68)$ & $<0.001$ \\
\hline
\end{tabular}

$a: \mathrm{p}$ value for Wilcoxon ranked sum test; IQR: interquartil range.

\section{TABLE IV}

Seroconversion rates in post-treatment serological assessments in Médécins Sans Frontières-Spain and Honduras Secretariat of Health project in Yoro, Honduras, 1999-2005

\begin{tabular}{|c|c|c|c|c|}
\hline & & \multirow[b]{3}{*}{$\mathrm{n}$} & \multicolumn{2}{|c|}{ Seroconversion rate } \\
\hline & & & 18 months & 36 months \\
\hline & & & $\mathrm{n} / \%(\mathrm{CI} 95 \%)$ & $\mathrm{n}^{a} / \%(\mathrm{CI} 95 \%)$ \\
\hline \multirow[t]{3}{*}{ Age (years) } & $<5$ & 65 & $58 / 89.2(81.7-96.8)$ & 63/96.9 (89.5-99.2) \\
\hline & $5-9$ & 70 & $61 / 87.1(79.3-95.0)$ & $66 / 94.3(86.2-97.8)$ \\
\hline & $\geq 10$ & 94 & $83 / 88.3(81.8-94.8)$ & $86 / 91.5(84.1-95.6)$ \\
\hline \multirow[t]{2}{*}{ Gender } & Male & 104 & $89 / 85.6(78.8-92.3)$ & $96 / 92.3(87.2-97.4)$ \\
\hline & Female & 125 & $113 / 90.4(85.2-95.6)$ & $119 / 95.2(91.5-98.9)$ \\
\hline Total & & 229 & $202 / 88.2(84.0-92.4)$ & $215 / 93.9(90.8-97.0)$ \\
\hline
\end{tabular}

$a$ : numbers of seroconverted cases at 36 months are cumulative; CI: confidence interval.

$(55.9 \%)$ did not have $a \geq 75 \%$ decrease in their antibody titres by the first assessment, but reached this percentage of decrease by the second assessment (McNemar test $\mathrm{p}<0.001$ ) (data not shown). No significant differences related to age or sex were found in the antibody titres or seroconversion rates (Tables II-IV).

\section{DISCUSSION}

Cost-efficacy analyses like the one carried out by MSF-E clearly show that vector control programmes that include Chagas disease treatment are much more effective than simply isolated vector control. These programmes have a direct influence on disease impact and prevalence as well as on morbidity and mortality (Wilson et al. 2005).

On the other hand, several controlled trials (Andrade et al. 1996, 2004, Coura et al. 1997, Sosa-Estani et al. 1998) and longitudinal studies with various benznidazole-based regimens (Ferreira 1990, Viotti et al. 1994, Gallerano \& Sosa 2000, Cançado 2002, Streiger et al. 2004) that were developed in Brazil, Argentina and Chile in the 1990s show that trypanocide treatment is generally effective in children and adolescents in the chronic latent phase; cure rates as high as $60 \%$ have been demonstrated through serological negative conversion (Andrade et al. 1996, 2004, Gallerano \& Sosa 2000). Based on these results, the PAHO/WHO made an official recommendation in favour of etiological treatment for children and young adults with the indeterminate form of chronic chagasic infection (PAHO/WHO 1998). The criteria for defining a cure in most of the quoted studies included ongoing negative results from conventional serological tests (Luquetti 1996, Cançado 1999, 2001, Coura \& de Castro 2002, Dias 2003).

A significant percentage of adverse effects can be mitigated by carefully monitoring patients with strict diagnostic and treatment follow-up protocols. In the present study, the intensity and characteristics of the observed adverse reactions did not differ substantially from those described by others (Villa et al. 2005, Guhl et al. 2008, Ponce 2008). In addition, we did not find differences from other studies in the rate of withdrawal of patients due to the side effects of benznidazole (Andrade et al. 1996, Sosa-Stani et al. 1998).

Our results corroborate the relevance of mid and long-term post-treatment follow-up in patients present- 
ing with the indeterminate chronic phase of Chagas disease. A significant proportion of cases that are still seropositive in the first assessment become negative by subsequent assessments, particularly in younger patients; in addition, we observed a high seroconversion rate in a relatively short period of time (3 years). Even though a significant percentage of patients who were followed for 36 months after completing their treatment remained seropositive $(14 / 27,51.9 \%)$, six patients $(42.9 \%)$ did show a clear tendency towards seroconversion and a significant reduction of antibody titres in the follow-up serology.

Some limitations must be considered in the interpretation of these results: only one serological test (recombinant ELISA) was used to assess the cure rate, the study was conducted with a non-controlled observational design and the investigation was not able to follow all of the patients for up to three years after treatment. Nevertheless, the high specificity of the recombinant ELISA justifies its use. We have not used a second serological test with different principles and antigens to verify cures, as recommended by the WHO, because of financial constraints, logistical complications and limited time and human resources.

In Honduras, the MSF-E designed treatment of seropositive patients was an important innovation in the fight against Chagas disease. Initially, recommendations for the national programme only focused on treating acute and congenital cases (Gergonne 2001).

Notwithstanding this fact, the supervised treatment of $T$. cruzi seropositive children has occurred in different ways throughout the country with community participation in an intervention area under surveillance. The first trial occurred between 1992-1993, when 45 children between the ages of six months and five years were treated in the municipality of San Marcos de Colón, Choluteca Department; these children reached $91.1 \%$ seroconversion two years after treatment (Ponce 2008).

In 2000 and parallel with the MSF-E project, MSFFrance launched another Chagas disease comprehensive care programme that included etiological treatment for the infected population under 13 years of age in the Francisco Morazán and Olancho Departments. Similar programmes were replicated by the HSH in Intibucá, El Paraíso and Francisco Morazán. The same MSF-E protocols were used based on the recommendations made by the WHO and HSH. The results, based on post-treatment serological assessments, showed a cure rate of $83 \%$ and $100 \%$, respectively, at 18 and 36 months after treatment (República de Honduras 2003a, Ponce 2008). A similar study carried out among schoolchildren between the ages of 4-15 years in Colombia in 2002-2003 (Guhl et al. 2008) revealed comparable results, with $94.4 \%$ seroconversion six months after treatment, exceeding by far the data reported by the studies carried out in the Southern Cone in the 1990's.

The aforementioned results coincide with our findings and contrast with other studies that show seroconversion rates of between $2.3 \%$ by two years after treatment and $65 \%$ by six years after treatment (Ferreira 1990, Viotti et al. 1994, Andrade et al. 1996, 2004, SosaStani et al. 1998, Gallerano \& Sosa 2000, Streiger et al. 2004). These differences are partly ascribed to the study designs (observational or experimental), various follow- up times, treatment patterns used (dose and duration), stages of the disease, ages of the patients and different serological assessment tests that were used (Coura \& de Castro 2002). Geographical diversity also plays an important role in these differences. T. cruzi strains in Central America, as confirmed by the clinical, epidemiological and experimental findings, result in a milder form of the disease and are more sensitive to treatment than those found in the Southern Cone below the Equator. This may be the result of a lesser exposure to benznidazole, which might also favour these differences (Devera et al. 2003, Miles et al. 2003).

The time that elapsed between the spraying of infested dwellings with residual insecticides and the treatment enabled us to assume that most of the children were in the indeterminate form of the early chronic phase of Chagas disease. Therefore, higher and faster seroconversion rates in our study cannot be attributed to a short time between the infection transmission and the treatment.

Our results clearly demonstrate the efficacy and safety of a specific treatment program for Chagas disease in young children living in endemic areas in Honduras. However, additional and larger therapeutic trials are needed in the country and in the Yoro Department region; these studies should include not only clinical results (mortality, incidence of sudden death and heart failure) but also in vivo and in vitro susceptibility studies of $T$. cruzi strains.

The information gathered throughout this project has produced several important results. First, the study has validated, at a local level, a treatment protocol for recent $T$. cruzi infections among populations in endemic rural areas under entomological surveillance where vector transmission has been interrupted. Second, MSF has been able to replicate and implement similar initiatives in other countries (including Nicaragua, Guatemala and Bolivia). Third, this study offers a starting point for the implementation of initiatives to fight against Chagas disease in Honduras through close collaborating with international institutions like the Japanese International Cooperation Agency, the Canadian International Development Agency and World Vision. Moreover, serological data obtained after treatment will be very useful to epidemiological surveillance of the disease in the country.

Finally, this study demonstrates that in areas where T. cruzi I is the predominant circulating parasite population and where $T$. cruzi II is responsible for the infection in humans, the diagnosis and treatment of Chagas disease is feasible, necessary and ethically indisputable.

\section{ACKNOWLEDGEMENTS}

To Dr. Yermi Chávez, counterpart doctor, Rossel López, the Environmental Health Officer of the HSH, and Lucas Aguilar, the laboratory technician, for their valuable support to develop this project, to all the MSF-E local staff, the municipalities and communities in the Yoro Department that participated in the project: civil and health authorities, vector control technicians, IEC staff, survey takers, nurses, doctors and community agents, to the HSH staff, for their commitment to search and follow-up of children after treatment completion, and to Dr. Gabriel A. Schmunis, for his valuable comments concerning a previous version of this manuscript. 


\section{REFERENCES}

Andrade AL, Martelli CMT, Oliveira RM, Silva SA, Aires AIS, Soussumi LMT, Covas DT, Silva LS, Andrade JG, Travassos LR, Almeida IC 2004. Benznidazol efficacy among Tripanosoma cruzi-infected adolescents after a six years of follow-up. Am J Trop Med Hyg 71: 594-597.

Andrade AL, Zicker F, Oliveira RM, Silva SA, Luquetti A, Travassos LR, Almeida IC, Andrade SS, Andrade JG, Martelli CMT 1996. Randomized trial of efficacy of benznizadol in treatment of early Trypanosoma cruzi infection. Lancet 348: 1407-1413.

Cançado JR 1999. Criteria of Chagas disease cure. Mem Inst Oswaldo Cruz 94 (Suppl. I): 331-335.

Cançado JR 2001. Etiological treatment of chronic Chagas disease. Rev Inst Med Trop Sao Paulo 43: 173-174.

Cançado JR 2002. Long term evaluation of etiological treatment of Chagas disease with benznidazol. Rev Inst Med Trop Sao Paulo 44: 20-37.

Coura JR, de Abreu L, Willcox HP, Petana W 1997. Comparative controlled study on the use of benznidazole, nifurtimox and placebo, in the chronic form of Chagas' disease in a field area with interrupted transmission. I. Preliminary evaluation. Rev Soc Bras Med Trop 30: 139-144.

Coura JR, de Castro SL 2002. A critical review on Chagas disease chemotherapy. Mem Inst Oswaldo Cruz 97: 3-24.

Devera R, Fernandes O, Coura JR 2003. Should Trypanosoma cruzi be called "cruzi" complex? A review of the parasite diversity and the potential of selecting population after in vitro culturing and mice infection. Mem Inst Oswaldo Cruz 98: 1-12.

Dias JCP 2003. Tratamiento etiológico de la enfermedad de Chagas: una síntesis. XIIa Reunión Intergubernamental INCOSUR/Chagas, Santiago, Chile, Marzo 2003. [cited 2008 Apr 10]. Available from: http://www.bvsops.org.uy/pdf/chagas11.pdf.

Ferreira HO 1990. Tratamento da forma indeterminada da doença de Chagas com nifurtimox e benznidazol. Rev Soc Bras Med Trop 23: 209-211.

Gallerano RR, Sosa RR 2000. Estudio de intervención en la evolución natural de la enfermedad de Chagas. Evaluación del tratamiento antiparasitario específico. Estudio retrospectivo-prospectivo de terapéutica antiparasitaria. Rev Fac Cienc Med Cordoba 57: 135-162.

Gergonne B 2001. Maladie de Chagas au Honduras. Contrôle vectoriel et traitement des enfants: suivi épidémiologique. Internal report, Epicentre, Paris, 75 pp.

Guhl F, Nichols RS, Montoya R, Rosas F, Velasco VM, Mora E, Herrera C, Santa Cruz MM, Pinto N, Aguilera G, Salcedo P, Zipa NY, Florez J, Olarte A, Castillo G 2008. Rápida negativización serológica después del tratamiento etiológico para enfermedad de Chagas en un grupo de escolares colombianos. Curso de Diagnóstico, Manejo y Tratamiento de la enfermedad de Chagas OPS/ MSF/SSA, p. 205-212. [cited 2008 Jun 5]. Available from: http:// www.mex.ops-oms.org/documentos/chagas/Capitulo\%202.pdf.

Luquetti A 1996. Etiological treatment for Chagas disease. Parasitology Today 13: 127-128.

Miles MA, Feliciangeli DM, Rojas de Arias A 2003. American trypanosomiasis (Chagas disease) and the role of molecular epidemiology in guiding control strategies. BMJ 326: 1444-1448.

Moncayo A, Ortiz-Yanine MI 2006. An unpdate on Chagas disease (human American tripanosomiasis). Ann Trop Med Parasitol 100: 663-677.
PAHO - Organización Panamericana de la Salud 2006. Estimación cuantitativa de la enfermedad de Chagas en las Américas. Washington DC OPS/HDM/CD/425-06, p. 6.

PAHO - Organización Panamericana de la Salud/WHO - Organización Mundial de la Salud 1998. Tratamiento etiológico de la enfermedad de Chagas. Conclusiones de una consulta técnica. Río de Janeiro, Brasil. OPS/HCP/HCT/140/99, p. 23-25

Ponce C 2007. Current situation of Chagas disease in Central America. Mem Inst Oswaldo Cruz 102 (Suppl. I): 41-44.

Ponce E 2008. Tratamiento etiológico de la infección asintomática por Tripanosoma cruzi en población menor de 15 años. Experiencias en Honduras. Curso de Diagnóstico, Manejo y Tratamiento de la enfermedad de Chagas OPS/MSF/SSA, p.213-216. [cited 2008 Jun 5]. Available from: http://www.mex.ops-ms.org/documentos/ chagas/Capitulo\%202.pdf.

República de Honduras 2003a. Secretaría de Salud. Dirección General de Salud. Programa Nacional de Control de la Enfermedad de Chagas. Plan Estratégico Nacional de Chagas PENCHAGAS 2003-2007, p. 7-9.

República de Honduras 2003b. Secretaría de Salud. Programa Nacional de Chagas. Agencia de Cooperación Internacional del Japón (JICA). Proyecto de Control de la Enfermedad de Chagas Reporte Anual 2003, p. 12-14.

República de Honduras 2004. Secretaría de Salud. Dirección General de Salud. Informe de actividades y resultados Programa Nacional de Chagas, p. 6-11.

Schofield CJ, Jannin J, Salvatella R 2006. The future of Chagas disease control. Trends Parasitol 22: 583-588.

Segovia JC 1913. Un caso de tripanosomiasis. Arc Hosp Rosales 8: $249-254$.

Sosa-Stani S, Segura EL, Ruiz AM, Velazquez E, Porcel BM, Yampotis C 1998. Efficacy of chemotherapy with benznidazole in children in the indeterminate phase of Chagas' disease. Am J Trop Med Hyg 59: 526-529.

Streiger ML, del Barco ML, Fabbro DL, Areas ED, Amicone ND 2004. Longitudinal study and specific chemotherapy in children with chronic Chagas' disease residing in a low endemicity area of Argentina. Rev Soc Bras Med Trop 37: 365-375.

Villa L, Escribà JM, Parreño F 2005. Resultados del tratamiento de la enfermedad de Chagas en menores de 15 años en el proyecto de Médicos Sin Fronteras en Tarija, Bolivia. Rev Pediatr Aten Primaria 7 (Suppl. 1): 61-76.

Viotti R, Vigliano C, Armenti H, Segura E 1994. Treatment of chronic Chagas' disease with benznidazole: clinical and serologic evolution of patients with long-term follow-up. Am Heart J 127: 151-162.

WHO - World Health Organization 2005. Tropical Disease Research Progress 2003-2004: Seventeen Program Report of the UNICEF/ UNDP/World Bank/WHO. Special Programme for Research and Training in Tropical Diseases, report 17. TDR/GEN/05.1. World Health Organization, Geneva, p. 31-33

Wilson LS, Strosberg AM, Barrio K 2005. Cost-effectiveness of Chagas disease interventions in Latinamerica and the Caribbean: Markov models. Am J Trop Med Hyg 73: 901-910.

Yamagata Y, Nakagawa J 2006. Control of Chagas disease. Adv Parasitol 61: 129-165. 